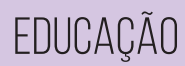

V.7 $\cdot$ N.3 • Abril -2019

ISSN Digital: 2316-3828

ISSN Impresso: 2316-333X

DOI: 10.17564/2316-3828.2019v7n3p41-54

ORCID: 0000000000000

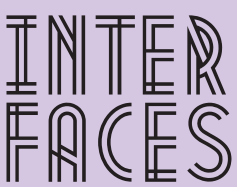

CIENTÍFICAS

\title{
A TEMÁTICA DAS DROGAS COMO ESTRATÉGIA PARA O ENSINO DE REACÕES QUÍMICAS
}

THE DRUGS THEME AS A STRATEGY FOR THE TEACHING OF CHEMICAL REACTIONS

LA TEMÁTICA DE LAS DROGAS COMOESTRATEGIA PARA LA ENSEÑANZA DE REACCIONES QUUIMICAS

João Batista dos Santos Filho ${ }^{1}$

Tatiana Santos de Araújo Batista ${ }^{2}$

Manuelânia Santos da Cruz ${ }^{3}$

\section{RESUMO}

Nos livros didáticos o assunto reações químicas é trabalhado de forma mecânica. Nossa tarefa como professores foi modificar o ensinar, isto é, a abordagem do tema foi fundada na integração do conceito de reações químicas e na discussão do aspecto social com a temática Drogas. 0 projeto foi desenvolvido com os alunos do primeiro ano do ensino médio, em uma escola pública de Aracaju-Sergipe. Foram utilizadas várias metodologias, entre elas um jogo lúdico de quebra cabeça, filme e aulas discursivas. Esse método foi satisfatório, permitindo verificar as dificuldades dos alunos, contribuindo para uma aprendizagem significativa e para formação de cidadãos conscientes e ativos.

\section{PALAVRAS-CHAVE}

Aprendizagem Significativa. Reações Químicas. Drogas. 


\section{RESUMEN}

In textbooks the subject of chemical reactions is worked mechanically. Our task as teachers was to modify teaching, that is, the approach to the theme was based on the integration of the concept of chemical reactions and the discussion of the social aspect with the theme "Drugs". The project was developed with students of the first year of high school, in a public school in Aracaju-Sergipe. Several methodologies were used, among them a playful game of puzzle, film and discursive classes. This method was satisfactory, allowing to verify the difficulties of the students and contributing to a significant learning and for the formation of conscious and active citizens.

\section{KEYWORDS}

Significant learning. chemical reactions. drugs.

\section{ABSTRACT}

En los libros didácticos el asunto reacciones químicas es trabajado de forma mecánica. Nuestra tarea como profesores fue modificar el enseñar, es decir, el enfoque del tema fue fundada en la integración del concepto de reacciones químicas y en la discusión del aspecto social con la temática "Drogas". El proyecto fue desarrollado con los alumnos del primer año de secundaria, en una escuela pública de Aracaju-Sergipe. Se utilizaron varias metodologías, entre ellas un juego lúdico de rompecabezas, película y clases discursivas. Este método fue satisfactorio, permitiendo verificar las dificultades de los alumnos y contribuyendo para un aprendizaje significativo y para la formación de ciudadanos conscientes y activos.

\section{PALABRAS CLAVE}

aprendizaje significativo. reacciones químicas. drogas. 


\section{INTRODUÇ̃̃̃O}

O ensino de Química na maioria das vezes vem sendo baseado em atividades que levam à memorização de informações, fórmulas e conhecimentos que limitam o aprendizado dos alunos, contribuem para a desmotivação em aprender e estudar Química. Não sendo observadas as limitações na forma como os conteúdos de Química estão sendo compreendidos pelos alunos. Essas limitações estão diretamente relacionadas com as dificuldades de abstração de conceitos, elaboração e compreensão de modelos científicos e o surgimento de concepções alternativas. Além disso, os alunos do ensino médio, geralmente apresentam baixos níveis de aprendizagens constatadas em avaliações internas realizadas no contexto da própria escola por professores e nas externas realizadas por programas de avaliações mantidos pelo Ministério da Educação (MEC).

É possível perceber que alunos e professores não compreendem os verdadeiros motivos para estudar e ensinar Química, ainda, parte da motivação parece estar relacionada com a futura profissão a ser seguida. Em oposição a esse pensamento, é importante estudar Química para possibilitar o desenvolvimento de uma visão crítica de mundo, podendo analisar, compreender, e, principalmente, utilizar o conhecimento construído em sala de aula para a resolução de problemas sociais, atuais e relevantes para sociedade (SANTOS, 2013).

Há uma necessidade de tornar a sala de aula dinâmica e interativa, valorizando a participação do aluno no processo de aprendizagem onde este participe direta e significativamente de sua própria aprendizagem, resolva problemas por si próprio, realizando tarefas relacionadas com os temas de estudo, para assim desenvolver os conhecimentos químicos, trabalhando mais articuladamente entre si e com suas vivências.

O tratamento dos conteúdos programáticos deve propiciar aprendizagem significativa, tendo o professor o compromisso com a formação da cidadania, onde o aluno não apresenta uma postura passiva e dogmática.

Nos livros didáticos o assunto reações químicas é trabalhado de forma mecânica, que compreende as classificações das reações, balanceamento das equações químicas e principais reações que envolvem as funções inorgânicas. Nossa tarefa como professores foi modificar o ensinar, isto é, a abordagem do tema foi fundada na integração do conceito de reações químicas e na discussão do aspecto social com a temática Drogas. Os temas químicos sociais desempenham papel fundamental no ensino de química para formar o cidadão, pois propiciam a contextualização do conteúdo químico com o cotidiano do aluno, permitindo o desenvolvimento das habilidades básicas relativas à cidadania, como a participação e a capacidade de tomada de decisão.

0 consumo de drogas é um ato antigo no contexto histórico da humanidade e se constitui num grave problema para os usuários e a sociedade. Segundo Moreira, Silveira e Andreoli (2006, p. 31) o consumo de drogas está presente na maioria das culturas, variando seus padrões de uso, suas funções, seu alcance e sua frequência. A especificidade do problema está nos seus caracteres conflitantes nos mais diversos níveis, seja ele individual ou social.

De acordo com os Parâmetros Curriculares Nacionais (PCN) (BRASIL, 1998, p. 273) as drogas psicoativas podem assumir um papel importante na vida dos adolescentes como recursos facilitadores da comunicação, da busca do prazer ou na lida como os novos desafios que se apresentam. No aspec- 
to social esse estudo permitiu contextualizar por intermédio da química a prevenção ao uso indevido de drogas já que o assunto gera muita preocupação entre os pais e professores.

Ausubel (1968) é um representante do cognitivismo e, como tal, propõe uma explicação teórica do processo de aprendizagem, segundo um ponto de vista cognitivista, embora reconheça a importância da experiência afetiva.

Quando se fala em aprendizagem segundo o construto cognitivista, está se encarando a aprendizagem como um processo de armazenamento de informação, condensação em classes mais genéricas de conhecimentos, que são incorporados a uma estrutura no cérebro do individuo, de modo que esta possa ser manipulada e utilizada no futuro. É a habilidade de organização das informações que deve ser desenvolvida.

A teoria de Ausubel focaliza primordialmente a aprendizagem cognitiva. Para ele aprendizagem significa organização e integração do material na estrutura cognitiva. Ausubel vê o armazenamento de informações na mente humana como sendo altamente organizado, formando uma espécie de hierarquia conceitual. Essa organização decorre, em parte, da interação que caracteriza a aprendizagem significativa.

Ausubel insiste em que a aprendizagem de que ele fala é ativa, embora seja receptiva. No final do processo de aprendizagem, o estudante deve provar que compreendeu e adquiriu significados relativos aos conceitos e proposições que lhe foram ensinados. Ele espera que haja retenção desses significados e, mais que isso, uma transferência dessa aprendizagem, provada por meio de uma aplicação dos significados adquiridos (AUSUBEL, 1968; MOREIRA, 1982).

\section{Exemplo:}

Segundo a teoria de Ausubel, suponha que se esteja preparando uma aula de Química para o $1^{0}$ ano do segundo grau e tenha como tema de lição Reações Químicas.

\section{Conteúdos potencialmente com sentido:}

O assunto Reações Químicas será mais ou menos significativo, dependendo do contexto em que for apresentado. Potencialmente deve ter sentido para uma turma de alunos repetentes ou que já tenham visto algo sobre 0 assunto na $8^{\circ}$ série.

\section{Organizadores avançados:}

Reações Químicas explicam como as substâncias podem se transformar, sofrendo alterações.

\section{Construtos inferidos - Processos}

1. Ancoragem: Conceito de transformações químicas é o assunto introdutório para a abordagem de Reações Químicas;

2. Estrutura Cognitiva: O maior subsunçor seria provavelmente o conceito de Reações Químicas a partir de exemplos simples, como a transformação da madeira em carvão, cinza e energia, ou o enferrujamento de um ferro.

\section{Processos}

1. Subsunção: Será necessário lançar mão de subsunçores correlativos. Será importante ressaltar que as Transformações Químicas são fenômenos integrantes das Reações Químicas;

2. Consolidação: Dependendo do nível de ensino, os alunos deverão não só serem capazes de distinguir um Fenômeno Físico de uma Reação Química, como também de dominar conceitos 
relativos a Conservação da Massa. Para que em aulas posteriores esses conceitos possam ser invocados para consolidação de novos conhecimentos.

Uma das vias mais promissoras para a melhoria da aprendizagem escolar consiste na melhoria dos materiais de ensino, e incluí aí os meios, dada sua óbvia relação com os materiais de ensino. Em seu último livro, Ausubel (1978) considera várias possibilidades para o uso de meios e sugere áreas em que são particularmente úteis. Ele usa o termo ajudas instrutivas em sentido genérico, e inclui todos os meios que os professores usam para propósitos educativos: livros, livros de exercícios, modelos esquemáticos, diagramas, demonstração, laboratórios, filmes, televisão, máquinas de ensinar etc.

Materiais impressos são considerados o melhor método de transmissão dos aspectos rotineiros dos conteúdos. Uma grande quantidade de materiais pode ser representada numa unidade limitada de tempo e o ritmo de apresentação e de assimilação fica sob o controle do aluno. No que se refere ao uso de laboratórios de ensino, Ausubel preconiza que devem se concentrar em experiências indutivas ou hipotético-dedutivas, reforçando assim a aprendizagem significativa.

A TV e os filmes apresentam vantagens e desvantagens. Como primeira vantagem o apresentador, via de regra, é uma pessoa mais habilitada que os professores. Ademais, os meios podem promover uma experiência vicária melhor do que a experiência direta com o professor. Por outro lado, uma desvantagem óbvia que é a ausência de contato direto entre o professor e os alunos, conquanto afirme não ser uma perda irremediável, uma vez que a presença do professor pode dar-se por meio de debates diretos ou de pequenos grupos, após a apresentação audiovisual.

As concepções de Vygotsky sobre o processo de formação de conceitos remetem às relações entre pensamento e linguagem, à questão cultural no processo de construção de significados pelos indivíduos, ao processo de internalização e ao papel da escola na transmissão de conhecimento, que é de natureza diferente daqueles aprendidos na vida cotidiana. Propõe uma visão de formação das funções psíquicas superiores como internalização mediada pela cultura.

Vygotsky tem uma grande preocupação com a aprendizagem por compreensão. Destaca-se como particularmente importantes a esse respeito três aspectos: sua contribuição sobre formação de conceitos e, em especial, dos conceitos científicos; seus estudos sobre o desenvolvimento da consciência e o papel que o sistema organizado de conceitos desempenha na direção desses processos; a sua contribuição sobre o papel do professor como mediador no processo de ensino/aprendizagem.

Vygotsky em seus estudos mostra que a tarefa de ser mediador exige um grande desenvolvimento de atitudes, uma delas é a de descobrir o que o aluno já sabe, ajudá-lo a reconstruir o seu próprio conhecimento. Outra atitude é a de levar o aluno a compreender o sentido do conteúdo, qual a relação que ele tem com sua vida, com seu mundo e com a sociedade na qual está inserido. A importância desse processo é que não basta que o professor atue sozinho, tem que haver uma disposição consistente e coerente da estrutura cognitiva. É necessário que o aluno ache o assunto relevante e significativo e assim estará reconstruindo-o na sua estrutura cognitiva (VYGOTSKY, 1987; VYGOTSKY, 1988; CARVALHO, 2007; NEVES, 2006; NÚNES, 2009; SCHNETZLER, 1995).

Segundo Vygotsky é necessário haver uma mudança na maneira de encarar o processo de ensino e aprendizagem. Ele ressalta que o conceito científico é muito importante para o desempenho da es- 
cola nos setores (ou classes) populares pelo apropriamento do entender (ou saber) cultural, pois isto ajuda na compreensão dos conceitos espontâneos que cada aluno traz dentro de si, e a partir daí vai adquirindo consciência por meio desses conceitos. Desde que este movimento seja bem trabalhado os alunos terão uma visão mais clara de muitas coisas que não conseguiam compreender.

Não há dúvidas que abordagem cognitivista da aprendizagem preconizada por Vygotsky é em defesa da classe baixa, tendo por objetivos transformar cada ser destas populações de oprimidos em sujeitos sociais conscientes e ativos (SCHNETZLER; ARAGÃO, 1995).

O objetivo deste estudo foi analisar as interferências de uma metodologia de ensino direcionada à formação do cidadão para que ocorra uma melhor aprendizagem. Para isso descreveu-se o processo de ensino-aprendizagem, desenvolvido a partir do tema Drogas para a construção dos conceitos de reação química, analisou-se os efeitos da metodologia empregada para a aprendizagem significativa dos conceitos de reação química e verificou-se o desenvolvimento da capacidade do aluno em se posicionar criticamente em relação ao uso das drogas.

\section{MATERIAL E MÉTODOS}

\subsection{A ESCOLA E OS ALUNOS - O CONTEXTO DA PESQUISA}

O projeto intitulado Contextualizando as Reações Químicas através da temática Drogas, foi desenvolvido com os alunos do primeiro ano do ensino médio, em uma escola pública de Aracaju-Sergipe, envolveu 10 aulas durante cinco semanas e contou com a participação de 38 alunos do ano letivo de 2016 do turno matutino. Os alunos apresentam faixa de idade entre 14 e 16 anos, todos residem em Aracaju e $90 \%$ têm a pretensão de cursar uma universidade.

\subsection{METODOLOGIA DE PESQUISA}

Antes de começado este trabalho fez-se um minucioso levantamento bibliográfico, a fim de se obter materiais que abordassem tanto o conteúdo de Reações Químicas, quanto o conteúdo social Drogas. Estas pesquisas foram feitas por meio de internet, livros e reuniões.

Logo que foi encontrado o material que se necessitava decidiu-se fazer a elaboração dos materiais que foram trabalhados, elaboraram-se os planos de aula, os roteiros de texto, pré-teste, pós-teste, questionários; duas listas diferentes sobre identificação de Reações Químicas, com o intuito de promover um debate entre os alunos; confecção de um quebra cabeça de balanceamento de equações químicas; lista de exercícios de vestibulares, visto que os alunos do ensino médio mostram uma grande preocupação com o vestibular; estudou-se o melhor filme para ser trabalhado o tema Drogas. Em suma, nessa fase foi feito um planejamento de tudo que foi realizado.

Em seguida foram elaborados os instrumentos de coleta, o pré-teste e o pós-teste. 


\subsection{PROCESSO DE ENSINO-APRENDIZAGEM}

Mediante pesquisas, questionários, podemos conhecer a turma, como também as necessidades informacionais, mostrou-se as informações que eles precisam ter.

A aplicação do projeto de pesquisa foi recebida com muito entusiasmo e euforia pelos alunos, isto, devido ao fato de ser uma grande novidade, já que eles são direcionados a uma metodologia que se baseia unicamente na preparação para o vestibular.

A aula foi introduzida com um texto, falando sobre drogas, momento que iniciou a discussão sobre o tema.

Em outras aulas foram trabalhados a identificação das Reações Químicas correlacionando com o tema gerador. Os educandos reagiram muito bem, com questionamentos e interesse mesmo se tratando de uma turma bastante agitada.

Durante as aulas foram utilizadas várias metodologias, entre elas o uso do jogo lúdico de quebra cabeça (um joguinho de reações químicas).

Por meio do pré-teste foi possível verificar as concepções prévias dos alunos e ao final de todo trabalho foi aplicado o pós-teste, pelo qual verificou-se a compreensão dos conceitos científicos. Foram aplicados questionários, lista de exercícios, a fim de se dar maior consistência, ou seja, maior compreensão da parte teórica.

Como forma de avaliação foi pedido para que os alunos confeccionassem cartazes sobre drogas para exposição no colégio; uma resenha escrita após assistirem o filme: Um Diário de Adolescente. 0 filme cujo tema central é drogas foi utilizado com o intuito de ampliar os conhecimentos dos alunos, para desenvolver a preservação social, vida e educação.

Realizou-se uma prova sobre o conteúdo de Reações Químicas e Drogas.

Todas as atividades e a participação dos alunos resultaram na avaliação com nota máxima de 10 pontos.

\section{RESULTADOS E DISCUSSÃO}

Mediante os resultados alcançados nota-se que os alunos já tinham um conhecimento prévio do assunto Reações Químicas e uma ampla visão do tema gerador Drogas e que suas concepções foram ampliadas e em alguns casos modificadas. Assim, as concepções prévias foram fortalecidas e serviram de ancoradouro para uma abordagem mais significativa do assunto.

Antes de representar as reações químicas por meio de equações, foi importante discutir algumas características desse tipo de transformação, como o fato de que as reações envolvem trocas de energia e que elas podem ocorrer em diferentes taxas, o que depende de fatores como temperatura, estado físico, superfície de contato e concentração dos reagentes, entre outros. Essa discussão foi bem introdutória, pois esses temas são normalmente abordados com mais detalhes no estudo de termoquímica, cinética e equilíbrio. Também, aqui foram usados fenômenos bem simples para evidenciar essas características. 
Por exemplo, analisou-se os efeitos provocados pelas drogas no organismo de um indivíduo, ou mesmo a dissolução do comprimido antiácido efervescente, usando água a diferentes temperaturas e o comprimido inteiro ou em pó foram exemplos simples que permitem evidenciar alguns desses fatores. Isso não só explicitou as ideias dos estudantes, mas também orientou a discussão dos fenômenos para uma descrição adequada das reações químicas, o uso de um raciocínio de identidade/transformação, com o reconhecimento do que muda e do que permanece constante na transformação, tanto no nível fenomenológico como no atômico molecular, foi essencial nessa descrição. Nesse sentido, a explicitação das concepções dos alunos não foi um fim em si mesmo, mas um ponto de partida para a construção de ideias cientificas sobre as reações químicas.

A verificação do rendimento compreendeu a avaliação do aproveitamento do processo ensino-aprendizagem. Os resultados da pesquisa realizada com os alunos por meio do pré-teste e pós- teste foram colocados em tabelas.

Na Tabela 1 observa-se que os alunos ampliaram seu conhecimento com relação à definição de uma reação química, pois no pré-teste observou-se que menos da metade dos alunos compreendiam que uma reação química origina uma nova substância e, no pós-teste, verificou-se que quase $90 \%$ da turma assimilaram esse conceito. Observa-se também que antes das aulas terem sido ministradas alguns alunos confundiam substância com elementos, mas durante as aulas discutiu-se a diferença entre ambos e foi explicado que numa reação química o que reage são as substâncias e não os elementos, e essa discussão teve um resultado positivo, que pode ser comprovado pela Tabela 1.

Nas Tabela 2 e 3 verificou-se os conhecimentos dos alunos com relação às drogas. Nenhum aluno definiu droga de forma cientifica, a maior parte relacionou a prejuízos, sejam na vida social, saúde, problemas e outros, enquanto que apenas alguns comentaram sobre a sua utilização em doenças, porém eles compreendem que o uso de drogas ao entrar em contato com o organismo dá origem a uma Reação Química.

Quando indivíduo usa drogas ele passa a sofrer uma série de reações, os sintomas, como tremores, alucinações, etc, são decorrentes do processo e transformação química que está ocorrendo no organismo com o efeito maléfico de cada droga. (Resposta da aluna TIANA DINIZ no pós-teste).

Com relação ao balanceamento de equações, observa-se por meio da Tabela 4 que houve um acréscimo no número de alunos que conseguem balancear e explicar o que é um balanceamento.

Quanto à classificação de reações, vê-se na Tabela 5 que a maioria dos alunos já sabia classificar as reações, no entanto no decorrer das aulas observou-se que esses tinham apenas uma visão mecanicista do conteúdo. Percebendo essa deficiência, trabalhou-se no sentido de explicar como as reações se processam e por que recebem tal classificação. Obteve-se bons resultados, pois $89,47 \%$ da turma mostraram compreender perfeitamente todos os tipos de reações.

Viu-se que, utilizando a análise do filme, os alunos conseguiram relacionar ciência e sociedade, ou seja, o assunto Reações Químicas com Drogas: 
Elas deprimiram meu sistema nervoso, estimularam minha mente. Tudo, através de uma simples reação química. Mas em toda reação há uma arrumação dos átomos, talvez a desta esteja mais para uma desorganização. Quem sabe uma desordem ordenada? (Trecho da análise de GABRIELA SOUSA).

Tabela 1 - Quanto aos fenômenos descritos no pré e pós-teste como os alunos definem reação química

\begin{tabular}{ccc}
\hline Categorias & Pré-teste (\%) & Pós- teste (\%) \\
\hline Transformação em uma nova substância & 36,84 & 89,47 \\
\hline Identificam como reação de oxidação (especificar) & 42,11 & 0,00 \\
\hline $\begin{array}{c}\text { Identificam como reação química, } \\
\text { mas não justificam corretamente }\end{array}$ & 13,16 & 10,53 \\
\hline Confusão entre substância e elemento & 5,26 & 0,00 \\
\hline Não responde & 2,63 & 0,00 \\
\hline
\end{tabular}

Fonte: Dados da pesquisa.

Tabela 2 - Opinião sobre as drogas

\begin{tabular}{|c|c|c|}
\hline Categorias & Pré-teste (\%) & Pós-teste (\%) \\
\hline $\begin{array}{l}\text { Definem como sendo algo prejudicial } \\
\text { a saúde e a vida social }\end{array}$ & 18,42 & 26,32 \\
\hline Definem como sendo prejudicial à saúde & 13,16 & 26,32 \\
\hline $\begin{array}{l}\text { Definem como sendo substâncias } \\
\text { capazes de provocar alucinações }\end{array}$ & 10,53 & 5,26 \\
\hline $\begin{array}{l}\text { Relaciona drogas a necessidade das pessoas fugirem } \\
\text { dos problemas }\end{array}$ & 10,53 & 2,63 \\
\hline $\begin{array}{l}\text { Falam que é benéfica somente quando } \\
\text { utilizada para doenças }\end{array}$ & 13,16 & 7,89 \\
\hline Definem como sendo ruins para o indivíduo & 34,21 & 28,95 \\
\hline Não responde & 0,00 & 0,00 \\
\hline
\end{tabular}

Fonte: Dados da pesquisa. 
Tabela 3 - Efeitos ou consequências das drogas na vida do indivíduo

\begin{tabular}{ccc} 
Categorias & Pré-tese (\%) & Pós-teste (\%) \\
\hline Morte & 15,79 & 0 \\
\hline Causam lesões no organismo & 44,74 & 26,32 \\
\hline Prejuízo na vida social & 7,89 & 28,95 \\
\hline Prejuízo na vida social e no organismo & 21,05 & 18,42 \\
\hline Prejuízo na vida social, organismo e podendo levar a morte & 10,53 & 23,68 \\
\hline Não responde & 0,00 & 2,63 \\
\hline
\end{tabular}

Fonte: Dados da pesquisa.

Tabela 4 - Com relação ao balanceamento de equações

\section{Categorias}

Apenas dizem se as equações estão ou não balanceadas

Conseguem balancear e explicar o que é um balanceamento

\section{Pré-teste (\%) Pós-teste (\%)}

10,53

81,58

89,47

Conseguem balancear uma equação, mas dizem não saber expor uma definição

$5,26 \quad 0,00$

Não entende balanceamento

2,63

Não responde

0,00

2,63

Fonte: Dados da pesquisa.

Tabela 5 - Quanto à classificação de equações

\section{Categorias}

Pré-teste (\%)

84,21

2,63
Pós-teste (\%)

89,47

Não acertaram nenhum tipo de equação 


\begin{tabular}{ccc}
\hline Categorias & Pré-teste (\%) & Pós-teste (\%) \\
\hline Apenas erraram um tipo de equação & 0 & 10,53 \\
\hline Apenas acertaram um tipo de equação & 5,26 & 0 \\
\hline Não sabem responder & 7,89 & 0 \\
\hline
\end{tabular}

Fonte: Dados da pesquisa.

Tabela 6 - Com relação ao enunciado da Lei de Lavoisier, dizem que

\begin{tabular}{ccc} 
Categorias & Pré-teste (\%) & Pós-teste (\%) \\
\hline A natureza está sempre se transformando & 57,89 & 0,0 \\
\hline $\begin{array}{c}\text { Reconhecem o enunciado da Lei de Lavoisier } \\
\text { Dizem que a massa dos reagentes } \\
\text { é igual à massa dos produtos }\end{array}$ & 13,16 & 0,0 \\
\hline $\begin{array}{c}\text { Dizem que já ouviu a frase, } \\
\text { mas não sabem explicar }\end{array}$ & 13,16 & 97,37 \\
\hline $\begin{array}{c}\text { Dizem que o homem é capaz de } \\
\text { transformar as coisas }\end{array}$ & 2,63 & 0,0 \\
\hline $\begin{array}{c}\text { Não sabem interpretar a frase } \\
\text { ina }\end{array}$ & 10,53 & 0,0 \\
\hline
\end{tabular}

Fonte: Dados da pesquisa.

\section{CONCLUSÃO}

O estudo teve a preocupação de observar como é que a metodologia dinâmica, realiza a organização e disseminação do seu material.

Foi possível verificar o rendimento dos alunos, fazendo uma comparação de seus conhecimentos prévios com a evolução dos conceitos. Esse método foi satisfatório, pois nos permitiu verificar as dificuldades dos alunos, bem como concluir que a metodologia do ensino contribuiu para uma aprendizagem significativa para formação de cidadãos conscientes e ativos. A adoção de formas alternativas de ensino, nesse caso, a aplicação do jogo didático, confecção de cartazes e filme sobre drogas se mostraram 
eficientes ferramentas pedagógicas para as aulas de Química, conseguindo atender às necessidades dos discentes, em relação ao conteúdo Reações Químicas de forma satisfatória e dinâmica.

Além disso, os estudantes mostraram-se entusiasmados e motivados durante as atividades propostas, pois a sala de aula foi transformada em um lugar agradável e atrativo. Na última aula, isso ficou mais evidente, quando os alunos falaram do quanto a metodologia foi produtiva e importante no seu processo de aprendizagem e que foi possível aprender química enquanto se divertiam.

\section{REFERÊNCIAS}

AUSUBEL, D. P. Educational psychology: a cognitive view. New York: Holt, Rinehart and Winston, 1968.

AUSUBEL, D. P.; NOVAK, J. D. Hanesian H. Educational psychology: a cognitive view. 2nd. ed. New York: Holt Rinehart and Winston, 1978.

BRASIL. Secretaria da Educação Fundamental. Parâmetros curriculares nacionais: terceiro e quarto ciclos: temas transversais. CAPRICHO, Maconha Acender ou não? Não! Brasília: MEC/SEF, 1998.

CARVALHO, H. W. P.; LIMA BATISTA, A. P.; RIBEIRO, C. M. Ensino e aprendizado de química na perspectiva dinâmico-interativa. Experiências em Ensino de Ciências, v. 2, n. 3, p. 34-47, 2007.

CHADWICK, C. B.; OLIVEIRA, J. B. A. Tecnologia educacional, teorias da instrução. 8. ed. Petrópolis: Vozes, 1984.

MORON, S. I. Subjetividade e constituição do sujeito em Vygotsky. Petrópolis: Editora Vozes Limitada, 2017.

MOREIRA, F. G.; SILVEIRA, D. X.; ANDREOLI, S. B. Redução de danos do uso indevido de drogas no contexto da escola promotora de saúde. Ciência e Saúde Coletiva, Rio de Janeiro, v. 11, n. 3, p. 807816, jul./set. 2006.

MOREIRA, M. A. Aprendizagem significativa. Brasília: Editora da UnB, 1999.

MOREIRA, M. A.; MASINI, E. F. S. Aprendizagem significativa, a teoria de David Ausubel. São Paulo: Moraes, 1982

NEVES, R. A.; DAMIANI, M. F. Vygotsky e as teorias da aprendizagem. UNI revista, v. 1, n. 2, p. 1-10, abril 2006. 
NÚNES, I. B. A formação de conceitos na perspectiva teórica de LS Vygotsky: aprendizagem e desenvolvimento. Brasília: Liber Livros, 2009.

SANTOS, A. O.; SILVA, R. P.; ANDRADE, D.; LIMA, J. P. M. Dificuldades e motivações de aprendizagem em química de alunos do ensino médio investigadas em ações do PIBID/UFS. Química, v. 9, n. 7, p. 1-6, 2013.

SCHNETZLER, R. P.; ARAGÃO, R. M. R. Importância, sentido e contribuições de pesquisas para o ensino de química. Química Nova na Escola, v. 1, p. 27-31, 1995.

VYGOTSKY, L. S. Pensamento e linguagem. São Paulo: Martins Fontes, 1987.

VYGOTSKY, L. S. A formação social da mente. 2. ed. São Paulo: Martins Fontes, 1988. 
Recebido em: 10 de Dezembro de 2017

Avaliado em: 29 de Março de 2018

Aceito em: 29 de Março de 2018

\section{田我回

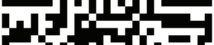

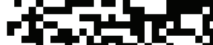

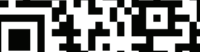

A autenticidade desse artigo pode ser conferida no site https://periodicos. set.edu.br
1 Doutor em física pela UFMG; Mestre em Física e Engenheiro eletricista pela UFS; Professor do Instituto Federal de Sergipe. E-mail: dr@joaobatista.eng.br

2 Doutora e Mestra em Física pela UFS; Graduada em Química licenciatura pela UFS; Professora do Instituto Federal de Sergipe. E-mail: tatiana.batista@academico.ifs.edu.br

3 Estudante de Graduação em Licenciatura em Química pelo IFS. E-mail: manu.scruz@live.com

\section{Como citar este artigo:}

SANTOS FILHO, João Batista dos; BATISTA, Tatiana Santos de Araújo; CRUZ, Manuelânia Santos da. A temática das drogas como estratégia para o ensino de reações químicas. Interfaces Científicas - Educação, Aracaju, v. 7, n. 3, p. 41-54, abr. 2019. DOI: 10.17564 /2316-3828.2019v7n3p41-54 Acesso em: 24 mar. 2019.

\section{(ㅇ) (1) (-)}

Este artigo é licenciado na modalidade acesso abertosob a Atribuição-Compartilhalgual CC BY-SA

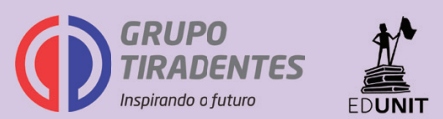

